\title{
0 eterno retorno do materialismo: padrões recorrentes de explicações materialistas dos fenômenos mentais
}

\author{
Materialism's eternal return: recurrent patterns of materialistic explanations of mental phenomena
}

\author{
Saulo de Freitas Araujo ${ }^{1}$ \\ 'Departamento de Psicologia, Universidade Federal de Juiz de Fora (UFJF), Juiz de Fora, MG, Brasil. \\ Texto previamente publicado em inglês como: Araujo SF. Materialism's eternal return: recurrent patterns of materialistic explanations of mental phenomena. In: Moreira-Almeida A, Santos FS \\ (Eds.). Exploring frontiers of the mind-brain relationship. New York: Springer; 2012.
}

Recebido: 12/4/2013 - Aceito: 15/4/2013

\begin{abstract}
Resumo
Com o desenvolvimento, na segunda metade do século XX, das novas tecnologias de neuroimagem para estudar o funcionamento do cérebro humano, uma nova onda de entusiasmo com as explicações materialistas dos fenômenos mentais invadiu os departamentos de filosofia e psicologia em todo o mundo. O auge de tudo isso foi a assim chamada "década do cérebro" nos anos 1990. Entretanto, um exame mais detalhado dos argumentos apresentados por esses novos materialistas revela padrões recorrentes de analogias e metáforas, além de uma velha estratégia retórica de apelar para um futuro distante, no qual todos os problemas serão resolvidos. Este trabalho pretende mostrar que essas novas formas de materialismo repetem estratégias discursivas de versões mais arcaicas do pensamento materialista, sobretudo do materialismo francês do século XVIII e do materialismo alemão do século XIX. Finalmente, uma interpretação para o eterno retorno do materialismo será oferecida.
\end{abstract}

Araujo SF / Rev Psiq Clín. 2013;40(3):114-9

Palavras-chave: Materialismo, problema mente-cérebro, fenômenos mentais, neurociência, filosofia da mente.

\begin{abstract}
Since the new developments of neurotechnologies for studying the brain functioning in the second half of twentieth century, a new wave of enthusiasm for materialistic explanations of mental phenomena has invaded philosophy and psychology departments worldwide. The culmination of all this was the so-called "decade of brain" in the 1990s. However, a closer examination of the arguments presented by some of these new materialists reveals recurrent patterns of analogies and metaphors, besides an old rhetorical strategy of appealing to a distant future, in which all the problems will be solved. This paper intends to show that these new forms of materialism repeat discursive strategies of older versions of materialism, especially the French materialism of the $18^{\text {th }}$ century and the German materialism of the 19th century. Finally, an interpretation for materialism's eternal return will be offered.
\end{abstract}

Araujo SF / Rev Psiq Clín. 2013;40(3):114-9

Keywords: Materialism, mind-brain problem, mental phenomena, neuroscience, philosophy of mind.

Para uma parte significativa de nossa sociedade moderna, o materialismo parece ser o resultado natural e inevitável do avanço das investigações científicas. De fato, essa imagem normalmente propagada e aparentemente irretocável de uma identidade entre ciência e cosmovisão materialista não deixa de ter certa legitimidade, na medida em que um número significativo de cientistas faz questão de afirmar sua adesão ao materialismo, além de dedicar parte de seu tempo à popularização dessa ideia. Entretanto, essa imagem não corresponde exatamente à realidade. Quando analisada mais de perto, ela se revela bastante limitada, além de problemática, na medida em que há também muitos cientistas que se posicionam claramente contra a visão de mundo materialista, demonstrando, assim, a independência entre ciência e materialismo.

O objetivo do presente trabalho é desmascarar essa falsa identidade e mostrar como ela tem gerado visões míticas sobre a natureza humana, tomando como exemplo as tentativas mais radicais na neurociência contemporânea de eliminar a autonomia da experiência subjetiva humana. Isso geralmente acontece em três estágios: inicialmente, algumas capacidades, previamente atribuídas aos seres humanos, são agora atribuídas ao cérebro ou a uma parte dele; em seguida, proclama-se uma completa fisicalização da natureza humana em geral, que é assim reduzida a um mero produto da atividade cerebral; finalmente, essa visão materialista é propagada como o resultado inevitável da ciência contemporânea.
Para atingir o objetivo anteriormente mencionado, o presente artigo será dividido em quatro partes. A primeira seção estabelece algumas definições conceituais, com o intuito de facilitar tanto a compreensão da ideia central quanto a sua discussão subsequente. A segunda seção mostra como uma parte significativa da neurociência contemporânea está comprometida com o materialismo e com a promessa de um novo futuro para a humanidade. A terceira seção mostra a grande similaridade entre alguns argumentos dos materialistas contemporâneos e as metáforas empregadas pelos materialistas dos séculos XVIII e XIX, caracterizando, pois, aquilo que eu chamo aqui de "o eterno retorno do materialismo". Finalmente, a quarta seção traz o argumento de que a assimilação e a reprodução acrítica e ingênua da ciência contemporânea favorecem a criação e a propagação de mitos e ideologias, contra os quais devemos estar sempre atentos.

\section{Definições preliminares}

Em primeiro lugar, é preciso esclarecer por que o materialismo não é uma teoria propriamente científica. Embora esteja hoje intimamente associado à imagem contemporânea de ciência, ele é, em seu sentido mais geral, uma tese metafísica acerca da natureza última da realidade, que unifica todo o campo da experiência humana, reduzindo-o, em última instância, a algum princípio explicativo derivado (válida ou invalidamente) do conceito de matéria, for- 
necendo ao final uma visão de mundo. Em outras palavras, o que identifica todo e qualquer defensor do materialismo é sua adesão à tese de que tudo o que existe no mundo é material( $\left.{ }^{1}\right)$. No entanto, uma afirmação desse tipo é tão geral e abrangente que jamais pode ser submetida a qualquer teste empírico particular, ultrapassando, portanto, a esfera do conhecimento científico possível. Ora, pelo menos desde a Crítica da Razão Pura ${ }^{1}$, não é mais possível ignorar que a totalidade do mundo é apenas uma ideia racional, mas não um objeto que possa ser dado na experiência. Da mesma forma que a matéria, pensada como condição última da experiência, também não pode ser confundida com nenhum fenômeno empírico particular, pois, nesse caso, ela teria que ser explicada por outra coisa diferente dela. Ou seja, se a matéria é pensada como o fundamento absoluto de toda experiência humana, ela mesma nunca pode aparecer como objeto de nossa experiência, permanecendo, pois, além do alcance do nosso conhecimento científico. Assim, uma vez que a ciência deve sempre estar solidamente amparada em evidências empíricas, nenhuma teoria científica, por mais bem estabelecida que esteja, pode implicar o materialismo. E é exatamente por isso que não podemos confundi-lo com uma teoria científica nem tratá-lo como se fosse uma. Logo, a expressão 'materialismo científico' pode servir no máximo para designar a posição ideológica ou o status profissional de seus adeptos (cientistas), mas de forma alguma ela significa que o que eles estão propondo seja uma teoria científica. Desfeita essa confusão, deve ficar claro que a legitimidade da ciência não depende da adesão do cientista à visão de mundo materialista, mas somente de seu compromisso com a lógica e a metodologia científica. Assim, tudo o que a ciência pode fazer é descobrir a existência de fenômenos e de suas relações, mas jamais a essência e a natureza última da realidade, já que estas últimas não podem ser dadas no nível empírico, requerendo, portanto, um conhecimento de outro tipo. Além disso, embora a prática científica possa estar atrelada a uma visão de mundo - como demonstram os estudos de Fleck $^{2}$ e Kuhn ${ }^{3}$, a ciência é uma atividade epistêmica em constante desenvolvimento, de forma que sua cristalização em uma visão de mundo seria contrária à sua própria natureza. Em suma, ciência e materialismo são coisas distintas, que só por um deslize conceitual podem ser tratadas como idênticas.

Essa primeira caracterização do materialismo ainda é insuficiente para fundamentar a ideia central deste artigo. É preciso introduzir um segundo esclarecimento, que diz respeito à diversidade de formas nas quais ele tem aparecido na tradição intelectual do ocidente. De fato, há diferenças contextuais específicas relacionadas ao surgimento de cada tipo de materialismo. Mas há também semelhanças importantes entre suas várias formas de manifestação. Isso é o que sustenta a clássica afirmação de Lange ${ }^{4}$, segundo a qual o materialismo é tão velho quanto a própria filosofia. Contudo, como há muitas concepções distintas do que seja a realidade última da matéria e também acerca de seu princípio explicativo fundamental, o materialismo encontra diferentes formas de expressão ao longo do tempo. Isso sem falar nos materialistas que nem sequer apresentam uma definição de matéria, tornando o rótulo ainda mais vago e abrangente. Sua primeira manifestação ocorre entre os gregos clássicos, com o atomismo de Leucipo e Demócrito, mais tarde revivido por Epicuro, cujo objetivo era explicar toda a realidade em termos do tamanho, da forma e do movimento dos átomos no vazio. Mas dos átomos de Demócrito e Epicuro até chegar à física contemporânea, podemos perceber que o termo "matéria" assume sentidos muito diferentes, o que consequentemente produz tipos

\footnotetext{
${ }^{1}$ Pode-se argumentar, é claro, que há formas mais fracas de materialismo, segundo as quais existem também números e outras entidades abstratas, que não podem ser reduzidas a estados ou processos materiais. Entretanto, não está claro para mim em que sentido elas poderiam ser propriamente chamadas de "formas de materialismo". Seja como for, meus argumentos são dirigidos apenas ao materialismo em suas formas mais fortes.
}

distintos de materialismo(2). Por isso, temos sempre que estar atentos para os diferentes sentidos que os termos "matéria" e "materialismo" podem assumir nos debates contemporâneos. Até porque, como já mencionado, existem tipos de materialismo que, na falta de uma noção explícita de matéria, apoiam-se seja em uma entidade física determinada (por exemplo, cérebro) seja em um princípio explicativo (por exemplo, seleção natural). Toda essa gama de usos potenciais de um único termo permite-nos vislumbrar o amplo espectro semântico do materialismo $4,8-10$.

Após essas considerações iniciais, eu gostaria então de definir o tipo de materialismo que eu tomarei como objeto de análise. Deixando de lado suas formas mais arcaicas, eu me concentrarei aqui no materialismo moderno, que surgiu na segunda metade do século XVIII, associado ao progresso das ciências da natureza, e permanece bem vivo nos dias atuais ${ }^{11,12}$. Nesse contexto, o que me interessa mais especificamente é um tipo de materialismo associado à neurociência, que elege o cérebro como entidade física onipotente e vê em suas propriedades o princípio explicativo fundamental para os fenômenos mentais. Em outras palavras, minha ênfase não recairá sobre o materialismo como teoria geral da realidade ou como visão de mundo, mas apenas como estratégia para explicar nossa experiência subjetiva.

\section{Materialismo e neurociência contemporânea}

Nas últimas décadas, temos presenciado um renovado interesse pelo materialismo. Um bom indicador disso é o número crescente de publicações acadêmicas recentes sobre o tema, que têm procurado mostrar tanto suas origens quanto sua atualidade10,13-16. Além disso, no próprio campo da filosofia da mente - disciplina que lida mais especificamente com o problema mente-cérebro - há várias tentativas recentes de explicar a mente humana em termos materialistas (por exemplo ${ }^{17-20}$ ). Isso para não falar nos recentes "manifestos" em defesa do materialismo, que cumprem um papel cultural mais amplo, ao apelarem para a completa conversão do leitor ao ateísmo ${ }^{21-25}$. Isso torna, a meu ver, extremamente problemática a tese de um enfraquecimento do materialismo 26 .

Mais especificamente, o que temos assistido é uma verdadeira onda de entusiasmo epistêmico motivado pelo contínuo e notável avanço das neurociências, em particular das novas tecnologias de neuroimagem. Por toda a parte, dentro e fora das universidades, surgem novos núcleos de estudo e/ou pesquisa dos processos cerebrais. A essa aposta na investigação do cérebro subjaz um otimismo explícito, que vê em um futuro não muito distante a solução de vários problemas concernentes à natureza humana. Basta aqui relembrarmos o entusiasmo com que foram anunciados e celebrados nos Estados Unidos, com recepção favorável em grande parte da comunidade científica internacional, o início da chamada "década do cérebro" (1990-1999) e suas promessas para as áreas da filosofia, da psicologia e da psiquiatria.

Analisando mais de perto esse entusiasmo geral, é possível perceber que uma de suas características fundamentais reside no fato de seus representantes estarem convencidos de que vivem a aurora de uma verdadeira revolução do pensamento humano, que irá transformar radicalmente a visão que temos de nós mesmos. Isso fica claro nas declarações de prestigiados representantes da neurociência e da filosofia contemporâneas:

"O advento de novas abordagens experimentais e técnicas de mapeamento e tratamento de imagens vai seguramente transformar nosso entendimento do cérebro humano. Que fantástico privilégio será para nossa geração - e a dos nossos filhos - testemunhar o que acredito que será a maior revolução na história da raça humana: entender a nós mesmos" $($ p. 21) 27 .

\footnotetext{
${ }^{2}$ As mudanças conceituais ocorridas ao longo do tempo na física oferecem uma boa indicação da complexidade e dos problemas envolvendo a noção de matéria ${ }^{5-7}$.
} 
"Uma teoria adequada da função cerebral apresentará um retrato incompatível ou significativamente diferente da natureza humana? Devemos nos preparar emocionalmente para outra revolução conceitual, que nos tocará ainda mais de perto que qualquer outra? [...] Estou inclinado a dar uma resposta positiva a todas estas questões e a avaliar positivamente nossas expectativas futuras, tanto em relação à moral quanto à ciência" (p. 18-19)28.

Ao investigarmos, contudo, o fundamento de todo esse otimismo, constatamos que ele se baseia primeiramente em uma insatisfação generalizada com toda forma de linguagem psicológica tradicional (mente, crença, vontade, intenção etc.), que esses autores atribuem à ingenuidade da nossa tradição dualista e religiosa ocidental. Eles argumentam que o senso comum já criou ilusões que foram posteriormente corrigidas pelo progresso científico (por exemplo, o caso das bruxas), e que isso vai igualmente acontecer em relação ao conhecimento da natureza humana com o avanço da neurociência, que se mostrará uma teoria superior. A seguinte passagem ilustra bem essa ideia:

"A existência das bruxas não era uma questão de controvérsia. [...] Mas, observáveis ou não, por fim chegamos à conclusão de que bruxas simplesmente não existem. Concluímos que o conceito de bruxa é um elemento de um arcabouço conceitual que interpreta de modo tão absolutamente incorreto os fenômenos aos quais ele era regularmente aplicado que seu emprego literal deveria ser permanentemente eliminado. As teorias modernas dos distúrbios mentais resultaram na eliminação das bruxas de nossa ontologia séria. Os conceitos da psicologia popular - crença, desejo, medo, sensação, dor, alegria, etc. - terão um destino análogo, segundo esse ponto de vista. E quando a neurociência tiver amadurecido a ponto de a pobreza de nossas atuais concepções ter se tornado manifesta a todos, e a superioridade do novo arcabouço tiver sido estabelecida, poderemos, por fim, dar início à tarefa de reformular nossas concepções das atividades e estados internos no interior de um arcabouço conceitual realmente adequado. Nossas explicações sobre os comportamentos uns dos outros irão recorrer a coisas como nossos estados neurofarmacológicos, nossa atividade neural em áreas anatômicas específicas e a outros estados que forem relevantes para a nossa teoria. Nossa introspecção individual também será transformada e poderá ser profundamente aprimorada em razão de um arcabouço conceitual mais penetrante e preciso - da mesma forma que a percepção do céu noturno pelo astrônomo foi em muito aprimorada pelo conhecimento detalhado da moderna teoria astronômica" (p. 81-82) 29 .

Um dos problemas centrais desse tipo de materialismo é que, na falta de dados empíricos consistentes, seus defensores se veem obrigados a apelar para um futuro bem distante, quase mítico, no qual todas as suas esperanças tornar-se-ão realidade. Ademais, esse apelo ao futuro nunca vem acompanhado de uma especificação mais precisa das condições necessárias e/ou suficientes para a concretização dessa nova revolução, ou mesmo da indicação de uma situação real que poderia falsificar sua proposta, o que nos permite suspeitar de que se trata aqui apenas de uma estratégia retórica, mas de forma alguma de uma hipótese científica ${ }^{3}$. Sendo assim, resta-nos apenas acreditar em uma promessa sem prazo para sua realização. É como se tivéssemos que comprar uma nota promissória sem saber quando poderíamos resgatá-la. Em outras palavras, tudo o que o materialista tem para nos oferecer é uma profecia, baseada na sua própria esperança, ou fé, de que uma revolução acontecerá no futuro. Há algumas décadas, Popper já tinha assinalado o problema fundamental com essa estratégia materialista:

\footnotetext{
${ }^{3} \mathrm{O}$ uso de estratégias retóricas na legitimação de teorias científicas parece ser um elemento essencial da ciência, como alguns estudos recentes têm mostrado ${ }^{30-36}$. Isso não significa, porém, que a ciência seja mera retórica ou que seja possível fazer ciência apenas com um discurso retórico.
}

"O materialismo promissor é uma teoria peculiar. Consiste, essencialmente, em uma profecia histórica (ou historicista) sobre os futuros resultados das pesquisas sobre o cérebro e o seu impacto. Esta profecia não tem fundamento. Nenhuma tentativa foi feita no sentido de fundamentá-la tendo em vista as recentes pesquisas sobre o cérebro. [...] Nenhuma tentativa foi feita no sentido de resolver as dificuldades do materialismo através de argumentos. Alternativas para o materialismo não são nem mesmo consideradas" (p. 131)37.

A falta de uma fundamentação sólida para a proposta materialista se torna mais evidente quando passamos a analisar sua relação com o avanço das investigações empíricas. De fato, passadas algumas décadas desde o início desse entusiasmo geral, podemos perguntar então se já temos pelo menos um esboço do que seria essa nova teoria neurocientífica da natureza humana. Apenas a título de ilustração, em uma recente coletânea de entrevistas com alguns dos mais destacados nomes nesta área - incluindo os principais expoentes do materialismo contemporâneo (por exemplo, Crick, Dennett e os Churchlands) -, descobrimos que, depois de 40 anos de pesquisas neurofisiológicas, não temos sequer um vislumbre de como resolver os problemas mais básicos acerca da consciência humana. No entanto, não faltam apostas e opiniões gerais muito vagas, na maior parte das vezes incompatíveis entre si ${ }^{38}$. E quando eles são questionados se ainda vai demorar muito para que a promessa se realize, a resposta mais precisa que recebemos vem da própria Patricia Churchland: "Nós realmente não sabemos quanto tempo teremos que esperar" (p. 56) ${ }^{39}$.

Gostaria de explorar esse ponto mais a fundo. Enquanto o futuro sonhado de uma superteoria não chega, o que os materialistas têm a nos oferecer é uma linguagem metafórica, quase ficcional, mediante a qual atribuem ao cérebro ou a partes dele uma série de capacidades e realizações que antes eram atributos da pessoa humana como um todo. Surge, assim, a "surpreendente hipótese" (the astonishing hypothesis) de que somos apenas um pacote de neurônios ou o somatório do comportamento de neurônios e suas moléculas ${ }^{40}$. Surgem, também, ideias como "o cérebro emocional" 41 , "o cérebro volitivo" 42 , "o cérebro executivo" 43 , "o cérebro crente" 44 , "o cérebro que modifica a si mesmo" 45 etc. Vejamos alguns exemplos de como essas metáforas são empregadas:

"Minha primeira suposição era a de que parte do cérebro tem a função de fazer planos para ações futuras, sem a necessidade de concretizá-las. [...] Minha segunda suposição era a de que não há consciência das computações feitas por esta parte do cérebro, mas apenas das decisões que ela toma - isto é, de seus planos. Então, uma máquina assim aparecerá para si mesma como tendo Livre Arbítrio, desde que ela possa personificar seu comportamento - isto é, que ela tenha uma imagem de si mesma" (p. 266) ${ }^{40}$.

"O hemisfério esquerdo estava realizando julgamentos emocionais sem saber o que estava sendo julgado. $\mathrm{O}$ hemisfério esquerdo conhecia o resultado emocional, mas não tinha acesso aos processos que produziram aquele resultado. Enquanto o hemisfério esquerdo estava envolvido, o processamento emocional acontecera fora de sua esfera da consciência (isto é, tinha ocorrido inconscientemente)" (p. 15)41.

"Permita-me ser o mais claro possível sobre o que eu quero dizer com 'sustentar crenças' ou ter um sistema de crenças. [...] Em geral, e esta é a minha visão sobre a natureza das crenças, nossa espécie reage instintivamente a eventos, e em um sistema especializado do cérebro humano esta reação é interpretada. A partir desta interpretação, emergem crenças sobre regras para a vida. [...] Sabemos agora que o hemisfério esquerdo do cérebro - aquele que associa uma história ao input do mundo externo - cria estas crenças. [...] Se o cérebro é modular, uma parte do cérebro deve estar monitorando todos os comportamentos da rede e tentando interpretar suas ações individuais para criar uma ideia unificada do self. Nosso melhor candidato para esta área cerebral é o 'intérprete do hemisfério esquerdo'. [...] Eu chamei esta área do hemisfério 
esquerdo de intérprete porque ele busca explicações para eventos internos e externos, e expande os fatos atuais de nossa experiência para dar sentido ou interpretar os eventos de nossa vida" (p. 146-150) ${ }^{44}$.

Descobrimos então, não sem um certo espanto, que o auge do nosso progresso científico consiste na substituição da noção de sujeito pela de hemisfério ou área cerebral. Quem agora "conhece", "faz avaliações", "interpreta", "cria", "procura explicações” etc. não é mais uma pessoa, mas sim um pedaço de matéria (parte do cérebro). Acontece que a utilização dessas metáforas encantadas, tomadas como explicações reais dos fenômenos, produz o resultado oposto do que era prometido, a saber, uma explicação científica. Afinal, não devemos esquecer que analogias e metáforas só são válidas quando, ao lado das semelhanças detectadas, também as diferenças são ressaltadas. Caso essas últimas desapareçam, então a relação passa a ser de identidade e não mais de analogia. ${ }^{4}$ Como procurei argumentar anteriormente ${ }^{52,53}$, a atribuição real de propriedades e capacidades psicológicas a objetos físicos é característica de um estágio bem primitivo da inteligência humana, a saber, o animismo, que todo materialista diz querer combater. E o que é pior, isso representa um retorno a uma metafísica muito menos crítica e ainda mais ingênua do que a que eles pretendem superar. Trata-se aqui, portanto, de pseudoexplicações, que de modo algum respondem às questões fundamentais, e cuja função é, mais uma vez, meramente retórica.

\section{0 eterno retorno}

Se acrescentarmos à análise até aqui realizada uma perspectiva histórica, esse novo entusiasmo em relação ao avanço da neurociência revela uma faceta ainda mais interessante, a saber, sua enorme semelhança com certos aspectos de versões anteriores do materialismo, o que coloca sob suspeita a questão da sua novidade. Como dissemos anteriormente, a associação do materialismo com as ciências naturais, especificamente com a fisiologia, é um fenômeno que surge no século XVIII, principalmente no contexto do iluminismo francês. Posteriormente, vai reaparecer na tradição alemã, por volta da metade do século XIX, ocasionando a chamada "querela do materialismo"14,15,54-56. Vejamos, primeiro, como o cérebro já aparece nesta tradição como causa última e suficiente para explicar os fenômenos mentais:

"Uma vez que as faculdades da alma dependem tanto da organização particular do cérebro e de todo o corpo, não sendo nada mais do que esta própria organização, trata-se aqui de uma máquina bem esclarecida!” (p. 94) 57(5).

"Todas as faculdades intelectuais, quer dizer, todos os modos de atuar atribuídos à alma se reduzem a modos de ser, modificações, qualidades e mudanças produzidas pelos movimentos do cérebro, que é em nós a causa visível da qual emana o princípio de todas as nossas ações. [...] Esse órgão se move, pois opera sobre si mesmo". (p. 97) ${ }^{58}$

"As operações da alma ou do espírito resultam de movimentos executados pelo órgão cerebral". (p. 40) ${ }^{59}$

"É inegável que a sede da consciência, da vontade, do pensamento deve ser enfim procurada unicamente no cérebro. Só que, por enquanto, ainda não nos foi possível determinar o modo pelo qual as engrenagens da máquina estão relacionadas" (p. 17) ${ }^{60(6)}$.

\footnotetext{
${ }^{4}$ Não se pode negar que a ciência tem se desenvolvido com o auxílio de metáforas e analogias $46-51$, mas uma teoria científica precisa de muito mais do que uma linguagem figurativa para ser estabelecida.

${ }_{5}^{5}$ Para a tradução das transcrições francesas, eu adotei dois procedimentos distintos. No caso de Holbach, usei uma edição inglesa correspondente à edição original. Em relação a La Mettrie e a Cabanis, fiz as traduções diretamente das obras originais em francês.

${ }^{6}$ As traduções das transcrições alemãs foram feitas diretamente das obras originais.
}

"Que o cérebro seja o órgão do pensamento e que ambos estejam em uma ligação imediata e necessária, que um não existe e não pode ser pensado sem o outro, é uma verdade da qual um médico ou fisiologista dificilmente pode duvidar" (p. 423)61.

Ainda mais interessante é a profusão de metáforas e analogias criadas para explicar como o cérebro pode produzir aquilo que chamamos de mente. Surge, então, a tradicional ideia de que os processos mentais são funções ou produtos da atividade cerebral, ideia esta bastante em voga nos debates atuais?

"Do mesmo modo que uma corda do violino ou uma tecla do cravo vibra e produz um som, as cordas do cérebro, afetadas pelos raios sonoros, são estimuladas para produzir ou repetir as palavras que as tocam" (p. 34) ${ }^{57}$.

"Para se ter uma ideia exata das operações que produzem o pensamento, é necessário considerar o cérebro como um órgão especial planejado especificamente para produzi-lo, assim como o estômago e o intestino são planejados para realizar a digestão, o fígado para filtrar a bile e as glândulas parótidas, maxilares e sublinguais para preparar os sucos salivares" (p. 152-153)

"Eu penso que todo cientista da natureza, ao pensar de forma lógica e consistente, chegará provavelmente à conclusão de que todas aquelas capacidades que nós apreendemos no conceito de atividades mentais são apenas funções da substância cerebral; ou, para me expressar aqui de forma mais rudimentar, de que os pensamentos relacionam-se com o cérebro da mesma maneira que a bílis com o fígado ou a urina com os rins" (p. 17)60.

"O pensamento é um movimento da matéria" (p. 284)63.

"Assim como a máquina a vapor produz movimento, o complexo orgânico de matéria evoluída com potencial energético gera no corpo animal uma soma de efeitos que, unificados, nós chamamos de espírito, alma, pensamento" (p. 443)61.

Essas passagens, tomadas aqui apenas como ilustração, já bastam para mostrar que os materialistas contemporâneos, ao anunciarem suas ideias como uma grande novidade, repetem estratégias discursivas e formas de raciocínio muito semelhantes às de seus correligionários do passado, sem que tenham consciência disso. $\mathrm{E}$ mesmo que não haja uniformidade ou consenso entre eles sobre o que seja precisamente o cérebro, como nos mostra a historiografia recente da neurociência (p. ex.., ${ }^{64}$ ), é essa atitude geral em relação a ele - assim como a fragilidade dos argumentos e a falta de dados empíricos para apoiá-la - que tem sido repetida, e que eu quero aqui enfatizar. É como se todo o período de nossa história intelectual que vai da segunda metade do século XVIII até o fim do século XIX fosse colocado entre parêntesis, para que essa nova aurora materialista possa soar como algo realmente novo. $\mathrm{Na}$ verdade, porém, trata-se apenas de uma nova roupagem para velhas esperanças, que acabaram se convertendo em um artigo de fé. É este fenômeno cíclico, que aparece em nossa cultura nos últimos 300 anos, que estou chamando de "o eterno retorno do materialismo".

Cabe, contudo, perguntar: haveria um sentido nesse eterno retorno? Num primeiro momento, podemos entendê-lo apenas como uma ingenuidade teórico-conceitual, oriunda do desprezo ou desconhecimento em relação à própria história da ciência e da filosofia. Mas nossa tese é a de que ele revela uma significação mais profunda, que diz respeito a uma falta de atenção para os limites epistêmicos do ser humano. Ou seja, o que todos os materialistas estão tentando, pelo menos desde o século XVIII, é eliminar a autonomia da dimensão subjetiva da experiência humana, reduzindo-a ou reformulando-a em termos da dimensão objetiva das ciências naturais. Na linguagem da filosofia da mente contemporânea, trata-se de explicar a

\footnotetext{
${ }^{7}$ John Searle, por exemplo, afirma em um de seus livros mais conhecidos: "Em minha opinião, temos que abandonar o dualismo e começar com o pressuposto de que a consciência é um fenômeno biológico comum, comparável ao crescimento, à digestão ou à secreção da bile" (p. 6)62.
} 
experiência de $1^{\text {a }}$ pessoa através do relato de $3^{\text {a }}$ pessoa, fato este que tem se revelado sistematicamente fracassado ${ }^{65-71}$. Ora, a abstração do sujeito nas ciências naturais é apenas um recurso metodológico, útil para a elaboração de teorias físicas precisas, mas de forma alguma uma prova de sua não existência ou de sua irrelevância para a compreensão da natureza humana. É como se dois zoólogos, nadando em um lago infestado de crocodilos famintos, acreditassem que ao parar de falar de crocodilos estariam eliminando o perigo iminente de serem devorados por estes. E é exatamente essa tentativa dos materialistas de eliminar a autonomia da esfera subjetiva que tem se mostrado fracassada ao longo do tempo. Nesse sentido, o eterno retorno do materialismo representa um eterno esquecimento, por parte de cientistas e filósofos, dos limites do conhecimento humano, não exatamente de seu conteúdo empírico, mas sim de suas condições universais. Ora, a perspectiva do sujeito da experiência parece não poder ser eliminada ou traduzida em uma linguagem puramente objetiva, embora possa ser correlacionada a esta última. Nesse caso, de nada adiantaria o acúmulo de novos dados empíricos para resolver os impasses e os paradoxos do materialismo contemporâneo. Isso nos permite suspeitar que a nova visão da natureza humana que os materialistas querem alcançar talvez seja utópica e ilusória, já que os limites das condições de nosso conhecimento científico permanecem inalterados.

\section{Observações finais}

Para finalizar minha reflexão, gostaria de explorar a relação entre ciência contemporânea e a criação de ideologias. Em primeiro lugar, é importante reafirmar que o materialismo não é uma consequência lógica e inevitável das pesquisas científicas. Se assim fosse, não poderia haver cientistas antimaterialistas. De fato, porém, muitos cientistas, desde o século XIX, vêm apontando os impasses da perspectiva materialista e sua impossibilidade de solução (p. ex.72,73). Além disso, muitos neurocientistas contemporâneos de grande prestígio são antimaterialistas ${ }^{74-78}$. Em segundo lugar, a exaltação e/ou reprodução ingênua e irrefletida de um falso ideal de ciência acaba levando à criação de mitos, que obstruem a compreensão do que seja realmente a atividade científica e de como ela se desenvolveu historicamente ${ }^{79-81}$. E é nesse contexto de uma assimilação acrítica da ciência contemporânea que corremos o risco de aceitar uma ideologia (cientificismo, materialismo científico) como se fosse um produto científico genuíno, e de participar de uma cruzada ideológica sem saber que se trata de uma. Ora, se a ciência tem uma função primordial, ela consiste na promoção do exame crítico da realidade, mas não na criação de histórias fantásticas e mitos alienantes. E se não podemos encontrar respostas definitivas para certas perguntas que temos levantado sistematicamente ao longo dos tempos, isso talvez aponte para certos limites de nosso conhecimento, o que nos obriga a recordar permanentemente os obstáculos que persistem, para não corrermos o risco de cair em novas formas de dogmatismo. Sendo assim, se a metafísica dualista é um resquício de nossa ingenuidade teórica e de nossa ignorância epistêmica, por que deveríamos considerar menos ingênua uma corrente de pensamento que atribui propriedades mágicas ao cérebro, transformando-o assim em um novo fetiche? No discurso neurocientífico contemporâneo, parece realmente haver menos ciência do que normalmente se imagina.

\section{Agradecimentos}

Sou grato a Alexander Moreira-Almeida, Chris Clarke, Luis Henrique Dreher e um parecerista anônimo pelos valiosos comentários que fizeram sobre uma versão inicial deste artigo, assim como à Fapemig pelo apoio financeiro.

\section{Referências}

1. Kant I. Kritik der reinen Vernunft (J. Timmermann, ed.). Hamburg: Meiner; 1998. (Texto originalmente publicado em 1781).
2. Fleck L. Genesis and development of a scientific fact. Chicago: The University of Chicago Press; 1979.

3. Kuhn T. The structure of scientific revolutions. 2nd ed. Chicago: The University of Chicago Press; 1970.

4. Lange F. Geschichte des materialismus und kritik seiner bedeutung in der gegenwart. Iserlohn: J. Baedecker; 1866.

5. Jammer M. Concepts of mass in classic and modern physics. Cambridge, Mass.: Harvard University Press; 1961.

6. Jammer M. The conceptual development of quantum mechanics. New York: McGraw-Hill; 1966.

7. Jammer M. Concepts of mass in contemporary physics. Princeton, N.J.: Princeton University Press; 2000.

8. Bloch E. Das materialismusproblem. seine geschichte und substanz. Frankfurt a.M.: Suhrkamp; 1972.

9. Campbell K. Materialism. In: Edwards P (Ed.) The encyclopedia of philosophy, vol. 5. New York: Macmillan Publishing; 1967. p. 179-88.

10. Moser P, Trout JD (Eds.). Contemporary materialism: a reader. London: Routledge; 1995.

11. Nieke W. Materialismus. In: Ritter J, Gründer K (Eds.), Historisches wörterbuch der philosophie, Bd. 5. Basel/Stuttgart: Schwabe \& Co AG; 1980. p. 842-50.

12. Bayertz K. Was ist moderner materialismus? In: Bayertz K, Gerhard M, Jaeschke W (Eds.) Der materialismus-streit. Hamburg: Meiner; 2007. p. 50-70.

13. Audidière S, Bourdin JC, Lardic JM, Markowits F, Zarka YC (Eds.). Matérialistes français du XVIIIe siècle. La Mettrie, Helvétius, d'Holbach. Paris: Presses Universitaires de France; 2006.

14. Arndt A, Jaeschke W (Eds.). Materislismus und spiritualismus. Philosophie und Wissenschaften nach 1848. Hamburg: Meiner; 2000.

15. Bayertz K, Gerhard M, Jaeschke W (Eds.) Der Materialismus-Streit. Hamburg: Meiner; 2007.

16. Boulad-Ayoub J, Torero-Ibad A. (eds.). Matérialismes des modernes. Nature et moeurs. Quèbec: Les Presses de l'Université Laval; 2009.

17. Melnyk A. A physicalist manifesto. Thoroughly modern materialism. Cambridge: Cambridge University Press; 2003.

18. Papineau D. Thinking about consciousness. Oxford: Clarendon Press 2002.

19. Ramachandran VS. A brief tour of human consciousness. New York Pi Press; 2004.

20. Tye M. Consciousness revisited. Materialism without phenomenal concepts. Cambridge, Mass.: The MIT Press; 2009.

21. Dennett D. Breaking the spell. Religion as a natural phenomenon. London: Penguin; 2006.

22. Dawkins R. The God delusion. London: Bantam Press; 2006.

23. Harris S. Letter to a Christian nation. New York: Alfred Knopf; 2006.

24. Hitchens C. God is not great. How religion poisons everything. New York: Twelve; 2006.

25. Onfray M. Traité d’athéologie. Paris: Grasset \& Fasquelle; 2005.

26. Koons R. Bealer G (Eds.) The waning of materialism. Oxford: Oxford University Press; 2010.

27. Ramachandran VS, Blakeslee S. Phantoms in the brain. Probing the mysteries of the human mind. New York: Harper Collins; 1998.

28. Churchland $P$. The engine of reason, the seat of the soul. A philosophical journey into the brain. Cambridge, Mass.: The MIT Press; 1996.

29. Churchland P. Matter and consciousness. Rev. ed. Cambridge, Mass.: The MIT Press; 1988.

30. Fahnestock J. Rhetorical figures in science. Oxford: Oxford University Press; 2002.

31. Gross A. The rhetoric of science. Cambridge, Mass.: Harvard University Press; 1996.

32. Gross A. Starring the text. The place of rhetoric in science studies. Carbondale: Southern Illinois University Press; 2006.

33. Irion C. Charles Darwin's "The Origin of Species": Science, rhetoric and revolution. München: Grin; 2008.

34. Moss J. Novelties in the heavens. Rhetoric and science in the Copernican controversy. Chicago: University of Chicago Press; 1993.

35. Shea E. How the gene got its groove. Figurative language, science, and the rhetoric of the real. Albany: State University of New York Press; 2009.

36. Stark R. Rhetoric, science, and magic in the seventeenth-century England. Washington, D.C.: The Catholic University of America Press; 2009.

37. Popper K. Materialism criticized. In: Popper K. Eccles J. The self and its brain. An argument for interactionism. New York: Routledge; 1983. p. 51-99. 
38. Blackmore S (Ed.). Conversations on consciousness. Oxford: Oxford University Press; 2006.

39. Churchland P, Churchland P. Patricia \& Paul Churchland. In: Blackmore S (Ed.). Conversations on consciousness. Oxford: Oxford University Press; 2006. p. 50-67.

40. Crick F. The astonishing hypothesis. The scientific search for the soul. New York: Touchstone; 1995.

41. Le Doux J. The emotional brain. The mysterious underpinnings of emotional life. New York: Touchstone; 1998.

42. Libet B, Freeman A, Sutherland K (Eds.). The volitional brain. Toward a neuroscience of free will. Exeter, UK: Imprint Academic; 1999.

43. Goldberg E. The executive brain. Frontal lobes and the civilized mind. Oxford: Oxford University Press; 2001.

44. Gazzaniga M. The ethical brain. New York: Dana Press; 2005.

45. Doidge N. The brain that changes itself. London: Penguin; 2009.

46. Baake, K. Metaphor and knowledge. Albany: State University of New York Press; 2003.

47. Brown, T. Making truth: Metaphor in science. Urbana: University of Illinois Press; 2008.

48. Hallyn F (Ed.). Metaphor and analogy in the sciences. Dordrecht: Kluwer; 2000.

49. Hesse M. Models and analogies in science. Notre Dame: University of Notre Dame Press; 1966.

50. Leary D. Metaphors in the history of psychology. Cambridge: Cambridge University Press; 1990.

51. Leatherdale W. The role of analogy, model and metaphor in science. New York: American Elsevier; 1974.

52. Araujo SF. Psicologia e neurociência: uma avaliação da perspectiva materialista no estudo dos fenômenos mentais. Juiz de Fora: Editora UFJF; 2003.

53. Araujo SF. Wie aktuell ist Wilhelm Wundts Stellung zum Leib-Seele-Problem? Schriftenreihe der Deutschen Gesellschaft für Geschichte der Nervenheilkunde, 12. 2006. p. 199-208.

54. Gregory F. Scientific materialism in nineteenth century Germany. Dordrecht: D. Reidel; 1977.

55. Meschede K. Materialismusstreit. In: Ritter J, Gründer K (Eds.). Historisches Wörterbuch der Philosophie, Bd. 5. Basel/Stuttgart: Schwabe \& Co AG; 1980. p. 868-9.

56. Wittkau-Horgby A. Materialismus. Entstehung und Wirkung in den Wissenschaften des 19. Jahrhunderts. Göttingen: Vandenhoeck und Ruprecht; 1998.

57. La Mettrie JO. L'Homme machine. Leiden: Elie Luzac; 1748.

58. Holbach B. System of nature or laws of the moral and physical world. Kitchener: Batoche Books; 2001. (Texto originalmente publicado em 1770).

59. Cabanis P. Rapports du physique et du moral de l'homme. Seconde Édition. Tome Premier. Paris: Crapelet; 1805.
60. Vogt K. Physiologische Briefe für Gebildete aller Stände. In: D. Wittich (Ed.). Schriften zum kleinbürgerlichen Materialismus in Deutschland, Bd 1. Berlin: Akademie-Verlag; 1971. p. 1-24. (Texto originalmente publicado em 1847).

61. Büchner L. Kraft und Stoff. In: Wittich D (Ed.). Schriften zum kleinbürgerlichen Materialismus in Deutschland, Bd. 2. Berlin: Akademie-Verlag; 1971. p. 343-516. (Texto originalmente publicado em 1855).

62. Searle J. The mystery of consciousness. New York: New York Review; 1997.

63. Moleschott J. Der Kreislauf des Lebens. In: Wittich D (Ed.). Schriften zum kleinbürgerlichen Materialismus in Deutschland, Bd. 1. Berlin: Akademie-Verlag; 1971. p. 25-341. (Texto originalmente publicado em 1852).

64. Hagner M. Homo cerebralis. Der Wandel vom Seelenorgan zum Gehirn. Frankfurt a.M.: Insel; 2000.

65. Chalmers D. The conscious mind. In search of a fundamental theory. Oxford: Oxford University Press; 1996.

66. Chalmers D. David Chalmers. In: Blackmore S (Ed.). Conversations on consciousness. Oxford: Oxford University Press; 2006. p. 37-49.

67. Frank M. Is subjectivity a non-thing, an absurdity? On some difficulties in naturalistic reductions of self-consciousness. In: Ameriks K, Sturma D (Eds.). The modern subject. Albany: State University of New York Press; 1995. p. 177-97.

68. Henrich D. Denken und Selbstsein. Vorlesungen über Subjektivität. Frankfurt a.M.: Suhrkamp; 2007.

69. Jackson F. Epiphenomenal qualia. Philosophical Quarterly. 1982;32:127-36.

70. Nagel T. What is it like to be a bat? Philosophical Review. 1974;83(4):435-50.

71. Nagel T. The view from nowhere. Oxford: Oxford University Press; 1986.

72. Du Bois-Reymond E. Über die Grenzen des Naturerkennens. In: Vorträge über Philosophie und Gesellschaft. Berlin: Akademie-Verlag; 1974. p. 54-77. (Texto originalmente publicado em 1872).

73. Wundt W. System der Philosophie. Leip; 1889.

74. Beauregard M, O'Leary D. The spiritual brain. A neuroscientist's case for the existence of the soul. New York: Harper Collins; 2007.

75. Eccles J. The human psyche. Berlin: Springer; 1980.

76. Eccles J. Part II. In: Popper K. Eccles J. The self and its brain. An argument for interactionism. New York: Routledge; 1983. p. 225-422.

77. Penfield W. The mystery of the mind. Princeton, N.J.: Princeton University Press; 1975.

78. Wallace A. The taboo of subjectivity. Toward a new science of consciousness. Oxford: Oxford University Press; 2000.

79. Midgley M. Science as salvation. A modern myth and its meaning. London: Routledge; 1994.

80. Midgley M. The myths we live by. London: Routledge; 2003.

81. Numbers D (Ed.). Galileo goes to jail and other myths about science and religion. Cambridge, Mass.: Harvard University Press; 2009. 